\title{
Fostering Early Numerical Skills at School Start in Children at Risk for Mathematical Achievement Problems: A Small Sample Size Training Study
}

\author{
Marcus Hasselhorn ${ }^{1} \&$ Kathrin Linke-Hasselhorn ${ }^{2}$ \\ ${ }^{1}$ German Institute for International Educational Research (DIPF), Center for Research on Individual \\ Development and Adaptive Education of Children at Risk (IDeA), Frankfurt, Germany \\ ${ }^{2}$ Grundschule Waldau (Waldau Public Elementary School), Kassel, Germany \\ Correspondence: Marcus Hasselhorn, German Institute for International Educational Research (DIPF), Center \\ for Research on Individual Development and Adaptive Education of Children at Risk (IDeA), Schloßstraße 29, \\ 60486 Frankfurt, Germany. Tel: 49-692-470-8214. E-mail: hasselhorn@dipf.de
}

\author{
Received: January 15, 2013 Accepted: January 25, 2013 Online Published: February 25, 2013 \\ doi:10.5539/ies.v6n3p213 \\ URL: http://dx.doi.org/10.5539/ies.v6n3p213
}

\begin{abstract}
Eight six-year old German children with development disabilities regarding such number competencies as have been demonstrated to be among the most relevant precursor skills for the acquisition of elementary mathematics received intensive training with the program "Mengen, zählen, Zahlen" ["quantities, counting, numbers"] (MZZ, Krajewski, Nieding, \& Schneider, 2007). In 24 30-minute training sessions administered across an interval of eight weeks, four children received the full program. Using a pretest-posttest control group design, the effectiveness of the training was demonstrated with a large effect size $(d=4.6)$. In addition, a shortened training of the waiting control group $(n=4)$ after finishing the principal evaluation replicated the appropriateness of the MZZ program $(d=2.5)$ as a means of remediating early number competence deficiencies at the onset of formal schooling.
\end{abstract}

Keywords: early education, poor early number competencies, cognitive training

\section{Introduction}

Societal and educational political expectations regarding pre-primary education and care have changed in a fundamental way in recent years. While attending kindergarten was for a long time predominantly attributed to socialisation, fostering the emotional, social, motor-related and moral development of children, recently many federal states in Germany presented orientation plans for pre-primary education and care that also target the preparation of specialized skills such as language competence, mathematics, and natural and life sciences. Furthermore, a significant change in guiding principles can be observed throughout the past decades: While until the 1960s, the prevailing opinion was to attribute learning achievement mainly to innate skills, this view has been substituted by the idea that school-based offerings can compensate for social disparities and provide for equal learning opportunities.

Findings from the first PISA study (Baumert et al., 2001) were interpreted as evidence for that this demand for compensation has so far been inadequately fulfilled by the German education system, or at least to a far less extent than this has been realized by other OECD countries. There is reason to believe that the comparatively poor outcomes of German secondary school students in PISA studies may not least be due to a neglect of pre-primary education: If it were possible to make disadvantaged children sufficiently "fit" at an early stage of the education process, this should also affect the later acquisition of competencies in a positive way.

Findings from the Munich SCHOLASTIK study (Weinert \& Helmke, 1997) in particular indicate that children starting primary education with a low level of achievement maintain their relative position until the end of their primary education, i.e. weaker/poorer pupils hardly seem to catch up on their peers. This also applies to the domain of mathematics. According to primary educational standards in mathematics issued by the German Standing Conference of Ministers of Cultural Affairs these standards are mainly concerned with developing skills in the following domains: 
- $\quad$ constructing an idea of numbers and understanding of operations,

- developing spatial competencies and distinguishing shapes,

- recognizing patterns and structures,

- developing concepts of size and competencies for measuring and comparing

- $\quad$ assessing data and frequency and developing elementary concepts of probability.

Early numerical skills that are relevant for later school learning processes are developed even at kindergarten age (e.g., Jordan, Kaplan, Locuniak, \& Ramineni, 2007; Krajewski \& Schneider, 2009: LeFevre, Fast, Swarchuk, Smith-Chant, Bisanz, Kamawar, \& Penner-Wilger, 2010). The development of a concept of numbers rests on the integration of different concepts, skills and abilities. In this context, special significance is at first sight attributed to "number skills" such as counting and grasping structured and unstructured quantities (cf. Clements \& Sarama, 2007). Early number competencies have been demonstrated to be predictive precursors of mathematics achievement in primary school, like the ability to apprehend the value of small quantities immediately, to make comparative judgements about small numbers and their quantities, to grasp counting principles, and to join and separate sets (e.g., Jordan, Kaplan, Rameneni, \& Locuniak, 2009).

\subsection{Development of Early Numerical Skills}

Krajewski (2003) conducted a longitudinal study assessing the mathematical competencies of pupils from six months before starting school until the end of the fourth primary school year, revealing a high correlation between precursor knowledge of quantities and numbers at German kindergarten age and mathematical achievement throughout primary school education. A large proportion of the mathematical achievement at primary education level can thus apparently be predicted on the basis of "number competence" and the ability to count as achieved by the end of kindergarten. Krajewski (2003) identified a general intellectual giftedness, working memory capacity and the speed of accessing long-term memory as unspecific precursors of a successful acquisition of primary school mathematics, which did not only influence mathematics, but also the acquisition of reading and writing skills. On the other hand, specifically math-related skills included an initial knowledge of quantities (seriation, comparing quantities, comparing lengths) as well as numbers (ability to count, knowledge of Arabic numbers, ability to calculate) and the speed to identify numbers (reading dice, reading images of numbers, connecting numbers).

Empirically, mathematical achievement can be better predicted on the basis of early competencies regarding quantities and numbers than from unspecific abilities (cf. Krajewski \& Schneider, 2009). However, besides impeding the acquisition of school mathematical skills (direct impact), weak intellectual abilities and a reduced working memory capacity aggravate the development of mathematical precursor skills even at pre-primary age (cf. Preßler, Krajewski \& Hasselhorn, 2013), which in turn also impedes the acquisition of school mathematics (indirect impact of intelligence and working memory). Children with low levels of intelligence and working memory capacity lag behind as to specific precursor knowledge even prior to entering primary school hence their conditions for a mathematical school career are unfavourable (cf. Grube, 2006).

In many countries, early childhood education committees have meanwhile issued education plans for children in pre-primary day-care institutions, calling for strengthening the development of learning relevant competencies in line with the developmental stages of the children, and furthering children's competencies right from the start. Fostering the early development of number competencies should thus be in line with a natural acquisition of early mathematical skills and focus on the targeted development of competencies relating to quantities and numbers. Krajewski (2008) describes possible milestones children should have accomplished by the time they start school with reference to Resnick's (1989) theory of mathematical understanding.

Even in early life, children obviously possess basic numerical skills (Krajewski, 2003, labels this Level I). Children are born with an ability to distinguish between quantities. However, this is apparently not due to an "innate sense of numbers", that is the competence to distinguish concrete numbers, but rather the ability to differentiate between the scopes and extents of quantities. Regardless of this, children often begin counting even before entering kindergarten. They use this counting procedure for gradually arranging numbers in the proper sequence. At this stage, the numbers are not yet connected to quantities, but they are rehearsed similar to the alphabet.

Once basic numerical skills are linked, approximately at kindergarten age, children become aware that number words are linked to quantities (Level II according to Krajewski, 2003) and they understand that each number specifies a quantity. This understanding is developed in two phases: On the one hand many three-year olds already understand that there are numbers that relate to a small quantity ("few, little"), and other numbers define 
larger quantities ("many", "much") or even very large quantities ("very much"). Since the children assign several numbers to these rough categories of quantities (e.g. 8 are "many" and 20 are "many", too) they are at this stage of their development not able to distinguish between the numbers within one category, thus they are not able to tell whether 8 or 20 means "more" (imprecise quantity to numbers-word linkage, level IIa). They will only be able to perform this precision later once they allocate counted quantities to the exact order of numbers (precise quantity to number-word linkage, $I I b)$. This punctiform allocation of quantities and numbers enables the children to grasp the concept that rising numbers represent rising quantities (8 is less than 20). Regardless of the concept of concrete numbers, children realize that quantities (e.g. many beetles) can be decomposed into part quantities (some beetles are standing upright, other beetles are lying on their backs) and that they can be altered by adding or removing articles (some of the beetles are flying away, some of the beetles remain here).

Once relations between the quantities can also be represented by numbers, children have reached the level of understanding relations between numbers (Level III according to Krajewski, 2008) - on the one hand, they are able to decompose numbers (out of the total of five beetles, three are standing upright and two are lying on their backs) and on the other hand, they are able to identify differences between quantities (e.g. three children in the blue group as opposed to five children in the red group), using numbers to express these relations (two more children in the red group). Since this third level already integrates an understanding of calculating operations and it is generally only acquired for certain in the first school year, the first two levels in particular should be regarded as relating to precursory mathematical competencies.

The relevance of the competence levels described above for later mathematical achievement at school was demonstrated in a longitudinal study, where about $25 \%$ of the variance in maths achievement at the end of primary education (grade 4) was predicted by individual differences in early quantity to number-word linkage assessed four years earlier prior to starting school (Krajewski \& Schneider, 2009).

\subsection{Promoting Early Numerical Skills}

In recent times, the conviction has been affirmed that children with math-related learning difficulties or developmental lags should receive specific training targeting mathematical precursor knowledge dealing directly with mathematical contents (e.g. Gersten, Jordan, \& Flojo, 2005). Appropriate means of representation that are considered particularly effective if used economically are required in order to achieve this goal. Such means of representation are models reproducing the context-free mathematical skeleton of concrete actions, and illustrating the abstract structure underlying the numbers. They serve the performance and verbalisation of abstract, symbolic operations and thus provide the basis for internalizing the abstract structure of numbers. While weaker students also benefit from support and incentives as regards the recognition of mathematical structures by means of abstract, symbolic activities, they cannot be expected to grasp the abstract mathematical concepts if only frequently confronted with numerical actions that are close to their own daily life (see Krajewski, 2003).

At present, mainly two scientifically evaluated programs are applied in Germany claiming to provide for fostering early numerical skills: the program "Komm mit ins Zahlenland" [Come into the land of numbers] (Friedrich \& de Galgóczy, 2004) and the program "Mengen, zählen, Zahlen" [quantities, counting, numbers] (Krajewski, Nieding, \& Schneider, 2007). The first program introduces numbers up to 10 in personalized fashion, inspiring imagination. The "numerical space" is interpreted in a daily life context, with a place of residence for each number in the land of numbers (including a house and garden): Each number is given a number doll, a singular history, a specific character and an unmistakeable identity. Furthermore, a number goblin and a number fairy create further opportunities for the children to use their imagination and immerse into the world of numbers. Pauen and Pahnke (2008) analysed the effects observed immediately after children aged three to six years had received ten weeks of training. They reported that the games of the program facilitated the acquisition of elementary abilities. Moreover, numerous number games and the creative allocation of numbers to quantities support the acquisition of an imprecise quantity to number-word linkage (level IIa). However, this concept is limited as regards the possibility of acquiring higher order competencies, particularly the relative difference of numbers (level III). The "animification" of the total numerical space that is so characteristic for this concept nevertheless seems problematic: There is a danger that the numbers representing a context-free symbol of numerical situations will be released from their abstract meaning and assigned emotions. This might cause the effect that the children regard the numbers as animated characters and mentally represent them accordingly, instead of perceiving them as abstract symbols. The low effectiveness of this program found in a more recent evaluation study with appropriate control groups matches this observation (Krajewski, Nieding, \& Schneider, 2008). 
The second program that is currently available in Germany, the Würzburg training program "Quantities, counting, numbers", aiming to promote early awareness of quantities, numbers and relations between numbers (MZZ; Krajewski, Nieding, \& Schneider, 2007), is based on the development model described above. It systematically builds up conceptual knowledge from practising basic skills to instruction in numerical structures, draws on means of representation that incorporate basic mathematical ideas particularly well, and offers a clear structure of the numerical space, allowing for effective problem solving strategies. MZZ tries to teach children the meaning of numbers in a playful manner. The abstract structure of numbers and of the numerical space is thus rendered "tangible" and "visible". During the playful practice children use materials that represent and clarify the structure of numbers. The children hence need not mentally deduct the abstract meaning of numbers themselves, but they gain fundamental insights into basic numerical knowledge by dealing with the objects as the means of representation, which they can grasp and compare.

The program comprises three focal areas of intervention. The first area focuses on training and linking basic numerical skills of the children (quantities, counting, numbers; competence level I). In due course, the children are expected to manage counting and numbers up to 10 and develop an awareness of the quantities underlying numbers (awareness of to linkage of quantities to number-words, competence level II). The second priority targets the understanding of numbers in terms of their rising sequence (precise quantity number-words linkage, competence level IIb). At this stage, the children are supposed to learn that numbers can be sequentially ordered and compared. The third priority addresses the fact that numbers are related in various ways. Children shall thus learn that numbers can be decomposed and re-composed to build different numbers, and that the difference between two numbers is a number itself (linking quantity relations with number-words, competence level III). These insights are promoted by support of visual representations and adequate verbal descriptions. The children are thus guided towards grasping numerical rules not only in a visual sense (e.g. greater numbers take up more space), but to becoming aware of such rules linguistically, and reasoning verbally (e.g. : " 4 is larger than 3, because more things belong to 4 than to 3"). A recent evaluation study has significantly demonstrated the training program's effectiveness with preschool children (Krajewski et al., 2008) as well as with primary school children suffering from intellectual disabilities (Kuhl, Sinner, \& Ennemoser, 2012).

\subsection{The Present Study}

Inspired by the positive evaluation of the MZZ program with preschool children and with primary school children suffering from intellectual disabilities, the present study aims to clarify whether the supporting effects of the program also pertain to children who display particularly severe deficiencies regarding the precursor skills that are so far assumed to be relevant for acquiring mathematical competencies in primary education. The authors of the MZZ program recommend its application in small groups of up to six children in order to support particularly weak children at kindergarten. For the purpose of our own study, we transfered this recommendation to children who were deferred from starting school at the regular age of school entry and who showed particular deficiencies in mathematical precursor competencies. In Germany, children are checked up for their school readiness about six months ahead of their regular school entry. Based on this assessment, about eight to ten percent of the children showing the lowest levels of school readiness are deferred from starting school the same year. In the present study, we tried to find out whether children deferred from regular school attendance with significant lags in their development of mathematical precursor skills might be successfully trained using the MZZ program.

\section{Method}

We used a classical pretest-posttest waiting control group design, randomly assigning the children for whom the training procedure was applicable to two groups. Initially, the MZZ was conducted with one group while at the same time the other group attended the general pre-school class along with other children. Following the intervention and the posttests, the training was also applied to the children from the second group.

\subsection{Assessment of Precursor Skills}

The relevant mathematical precursor skills were assessed using the mathematical basic interview EMBI from Peter-Koop, Wollring, Spindeler and Grüßing (2007), which links up to the primary educational standards for mathematics in assessing competence development in the area of "numbers and operations". EMBI is a German adaptation of an Australian one-to-one interview designed for pre-service teachers for understanding and assessing children's mathematical thinking (McDonough, Clarke \& Clarke, 2002). EMBI enables an assessment of precursor math skills in the so-called V-part (Vorschule = pre-school) comprising three areas: V1: Simple counting tasks /constancy of quantities; smaller/larger; V2: location relations, patterns, ordinal numbers; V3: simultaneous assessment/ allocation of numbers to quantities, allocation/ one-to-one-allocation. Based on 
Krajewski's (2003) model of early mathematical competencies, i.e. "one-to-one allocation", "counting", "invariant quantities", "seriation", "simultaneous assessment", "comparing", "cardinal number" and "ordinal number", 15 of the 21 tasks children have to master according to EMBI can be assigned to these relevant precursor skills. The competence levels of the children in the area of early numerical skills were thus determined according to the following EMBI requirements: sorting by colour, number of yellow bears, comparing numbers, counting off 5 blue bears, constancy of quantities, ordinal numbers, simultaneous assessment, number-quantities-assignment, allocation of the number symbol, part-whole-relations, successor, predecessor, one-to-one allocation, sorting three pencils, sorting 4 pencils.

\subsection{Participating Children}

63 children who were to be enrolled in one of three pre-school classes in a primary school in Northern Hesse, Germany, were subjected to an EMBI assessment while attending kindergarten the summer before. Children who managed to correctly meet fewer than nine of the 15 EMBI task requirements classified as relevant for early mathematical competencies were identified as "children at risk". 19 children were thus identified (ca. 30\%). 11 of these "children at risk" were enrolled in one of the three regularly first year primary school classes, with a fairly equal distribution across the three classes. The remaining eight children were among the children who were deferred from regular school attendance under consideration of general cognitive and socio-emotional criteria, thus they were enrolled in the pre-school (preparatory) class of the primary school. These eight deferred children who displayed a disadvantageous development regarding relevant mathematical precursor skills constituted the sample of children at risk for mathematical achievement problems in the present intervention study.

\subsection{Conducting the Training and Assessing its Effectiveness}

The training was conducted throughout the first months of the pre-school year. The eight "children at risk" were randomly assigned to two groups for intervention, comprised of four children each. The training was administered to each one of the groups in succession, allowing for an assessment of the training's effectiveness after the first group had received the program and comparing its achievement with the second group. Accordingly, the children in the group that had first been administered the training became the "training group", while the children in the second group became the "waiting control group" (initially serving as the control group, still waiting for training, receiving training subsequent to the first group).

The intervention program for the training group was conducted in a separate room three times per week during regular lessons. At these times, the children from the waiting control group participated in the regular pre-school class lessons. Pursuant to the MZZ manual, the program was realized in 24 training sessions each lasting 30 minutes. A playful atmosphere was taken care of throughout the exercises, ensuring that the children could concentrate on the tasks at hand without feeling pressed to achieve.

All eight children were once again interviewed pertinent to the V-part of the EMBI the week immediately following the completion of the training. The individual interviews lasted approximately 20 minutes per child. The children from the waiting control group then attended a slightly abbreviated MZZ program (only 18 training sessions lasting 30 minutes each could be applied here, within a period of six weeks). Some of the repetition units were thus either shortened or deleted. The four children in the waiting control group were subsequently interviewed with the V-part of the EMBI.

\section{Results}

The number of correctly fulfilled requirements according to the 15 relevant early mathematical skills addressed by the EMBI was assessed in a first assessment grid. Table 1 lists the summarized scores for each child, separated by group (training group vs. waiting control group) and time of measurement (pre vs. post). 
Table 1. Number of correctly solved relevant tasks from EMBI for all of the children included in the study, prior to and after conducting the MZZ, separated by training group and waiting control group

\begin{tabular}{lllll}
\hline & pre & post & change \\
\hline Training group & & & 12 & +7 \\
& Child 1 & 5 & 10 & +6 \\
& Child 2 & 4 & 11 & +5 \\
Child 3 & 6 & 12 & -5 \\
Child 4 & 7 & & -1 \\
Chiting control group & & 4 & +3 \\
Child 1 & 5 & 7 & -3 \\
Child 3 & 8 & 9 & 3 & \\
\hline
\end{tabular}

Note: Maximum value 15

As can be seen in Table 1, all the children in the training group displayed a significant increase in the number of correctly solved task requirements. Even though none of the children was able to correctly meet all 15 relevant tasks of the EMBI, the average number of solved tasks does at least amount to $M=11.25(S D=0.96)$. This corresponds to an increase rate of 5.75 additionally solved tasks. Throughout the same period of time, only one of the four children from the waiting control group displayed an increase in the number of correctly solved tasks. On average, no improvement at all is observable for the waiting control group. A 2 (group) x 2 (measurement point) factorial analysis of variance with repeated measurement of the measurement point (pre- vs. posttest) did not produce any main effect at the previously determined level of significance $(\alpha=.05)$ for $\operatorname{Group}(F(1,6)=5.55$ $p>.05)$. Nevertheless, despite the extremely low test power, a statistically significant main effect was found for measurement point $(F(1,6)=15.21, p<.01)$ and also a significant interaction between group and measurement point $(F(1,6)=21.55, p<.01)$. Subsequent mean comparisons revealed a statistically significant advantage regarding the change in achievement of the training group as opposed to the waiting control group. The effect size of the training effect amounts to $d=4.6$.

In a second assessment grid we analysed the changes among the children from the waiting control group at a time when these children had also received the MZZ intervention. Table 2 indicates the number of correctly solved relevant tasks from the EMBI immediately before (pre), and after completing the MZZ intervention six weeks later (post).

Table 2. Number of correctly solved relevant tasks from EMBI for children in the waiting control group, before and after receiving the $\mathrm{MZZ}$ intervention

\begin{tabular}{cccc}
\hline & pre & post & change \\
\hline Child 1 & 4 & 13 & +9 \\
Child 2 & 7 & 11 & +4 \\
Child 3 & 9 & 11 & +2 \\
Child 4 & 3 & 9 & +6 \\
\hline
\end{tabular}

Note: Maximum value 15

Table 2 illustrates that all four children from the former control waiting group benefited from the shortened MZZ intervention; with the increase rate varying from 2 to 9 additional correctly solved relevant tasks with an average increase rate of 5.25, which is only slightly lower than the increase rate identified for the training group with the full MZZ intervention. The average number of the tasks that were correctly solved after receiving the training is also only slightly lower in this "second training group" $(M=11.0)$. The repeated measurement analysis of variance on the change of the number of successfully solved EMBI tasks from pre- to posttest reveals a statistically significant effect of the change despite the low test power $(F(1,3)=12.36, p<.05, d=2.5)$. Even though owing to time constraints, only an abbreviated version of the training program could be administered to this second group, the effectiveness of the MZZ could be confirmed again. 


\section{Discussion}

The objective of this study was to test the effectiveness of the MZZ program for supporting children at the age of school entry who display strikingly poor early numerical skills. On the whole, the intervention proved to be highly effective for all of the trained children, i.e. all of the children were able to solve more EMBI tasks from the area of relevant early mathematical skills after they had received the training. At first sight, this is a distinctive result, even more so because the training effects are very strong, amounting to $d=2.5$ for the reduced training in the waiting control group and $d=4.6$ for the group receiving the complete training. Still, does this also mean that the MZZ presents an appropriate approach to fostering children that can prevent all risks affecting mathematics achievement? Such a consequence would be prematurely drawn as the following thoughts regarding the limitations and remaining questions suggest.

One of the first problems emerges from the time of administering the training, which was deliberately set early, at the beginning of the pre-school year. The children receiving the exercises were neither attending kindergarten nor the first primary school year, but they were school-aged children who had been deferred from attending regular school instruction. The evaluation of the MZZ introduced by Krajewski et al. (2007) suggests that training children with the MZZ should best be conducted shortly before the children start school, in order to increase the probability of the effects being transferred to school achievement. Accordingly, training the children during the last four months of their pre-school year might bear a stronger impact on elementary mathematical skills at school than training them nearly a full year before they start their first year at school, as this was the case here. Our study does not allow for drawing any conclusions whatever about possible long-term effects.

We should moreover not disregard that the study presented here might lead to a near-sighted perception of the educational mandate, for instance by reducing the fostering of mathematical skills in early learning to the prevention of calculating disorders in the year prior to school enrolment. Certainly, the prevention of mathematical learning disorders constitutes an important aspect of pre-school support, particularly as current research suggests that school achievement can even be predicted before starting school, and respective early intervention by appropriate means of illustration and representation has a positive effect on primary school achievement. Nevertheless, we should not fully disregard the fact that the educational mandate for early education is based on an extended concept of competencies, also with regard to the educational standards for mathematics in primary education.

A final question is: What is the practical meaning here? Can we make concrete recommendations? The MZZ can apparently be successfully conducted in kindergarten and pre-school classes and it should be conducted there, too, because it is apt for preventing calculating disorders. However, despite the positive effects of intervention in the present study, many aspects remain to be clarified from an empirical point of view. One of these remaining issues concerns the demonstration of long-term positive achievement effects for the trained children regarding their mathematical skills.

\section{References}

Baumert, J., Klieme, E., Neubrand, M., Prenzel, M., Schiefele, U., Schneider, W., Stanat, P., Tillmann, K. J., \& Weiß, M. (Hrsg.) (2001). PISA 2000: Basiskompetenzen von Schülerinnen und Schülern im internationalen Vergleich [PISA 2000: Basic competencies of students in international comparison]. Opladen: Leske + Budrich.

Clements, D. H., \& Sarama, J. (2007). Early childhood mathematics learning. In F. K. Lester (Ed.), Second Handbook of Research on Mathematics Teaching and Learning (pp. 461-555). New York: Information Age Publishing.

Friedrich, G., \& de Galgóczy, V. (2004). Komm mit ins Zahlenland: Eine spielerische Entdeckungsreise in der Welt der Mathematik [Come into the land of numbers: A playful journey to the world of mathematics]. Freiburg: Christophorus Verlag Herder.

Gersten, R., Jordan, N. C., \& Flojo, J. R. (2005). Early identification and interventions for students with mathematics difficulties. Journal of Learning Disabilities, 38, 293-304. http://dx.doi.org/10.1177/00222194050380040301

Grube, D. (2006). Entwicklung des Rechnens im Grundschulalter: Basale Fertigkeiten, Wissensabruf und Arbeitsgedächtniseinflüsse [Development of arithmetics in elementary school years: Basic skills, knowledge retrieval, and working memory influences]. Münster: Waxmann. 
Jordan, N. C., Kaplan, D., Locuniak, M. N., \& Ramineni, C. (2007). Predicting first grade math achievement from developmental number sense trajectories. Learning Disabilities Research \& Practice, 22, 36-46. http://dx.doi.org/10.1111/j.1540-5826.2007.00229.x

Jordan, N. C., Kaplan, D., Ramineni, C., \& Locuniak, M. N. (2009). Early math matters: Kindergarten number competence and later mathematics outcomes. Developmental Psychology, 45, 850-867. http://dx.doi.org/10.1037/a0014939

Krajewski, K. (2003). Vorhersage von Rechenschwäche in der Grundschule [Prediction of mathematics difficulties in elementary school children]. Hamburg: Kovac.

Krajewski, K., \& Schneider, W. (2007). Prävention von Rechenstörungen [The early prevention of math problems]. In W. v. Suchodoletz (Hrsg.), Prävention von Entwicklungsstörungen (pp. 97-114). Göttingen: Hogrefe.

Krajewski, K., \& Schneider, W. (2009). Early development of quantity to number-word linkage as a precursor of mathematical school achievement and mathematical difficulties: Findings from a four-year longitudinal study. Learning and Instruction, 19, 513-526. http://dx.doi.org/10.1016/j.learninstruc.2008.10.002

Krajewski, K., Nieding, G., \& Schneider, W. (2007). Mengen, zählen, Zahlen. Die Welt der Mathematik verstehen (MZZ)[Quantities, counting, numbers. Understanding the world of mathematics]. Berlin: Cornelsen.

Krajewski, K., Nieding, G., \& Schneider, W. (2008). Kurz-und langfristige Effekte mathematischer Frühförderung im Kindergarten durch das Programm, Mengen, zählen, Zahlen“ [Short-and long-term effects of early mathematics prevention in kindergarten by the program, Quantities, Counting, Numbers"]. Zeitschrift für Entwicklungspsychologie und Pädagogische Psychologie, 40, 135-146. http://dx.doi.org/10.1026/0049-8637.40.3.135

Kuhl, J., Sinner, D., \& Ennemoser, M. (2012). Training quantity-number competencies in students with intellectual disabilities. Journal of Cognitive Education and Psychology, 11, 128-142. http://dx.doi.org/10.1891/1945-8959.11.2.128

LeFevre, J. A., Fast, L., Skwarchuk, S. L., Smith Chant, B. L., Bisanz, J., Kamawar, D., \& Penner Wilger, M. (2010). Pathways to mathematics: Longitudinal predictors of performance. Child Development, 81, 1753-1767. http://dx.doi.org/10.1111/j.1467-8624.2010.01508.x

McDonough, A., Clarke, B., \& Clarke, D. M. (2002). Understanding, assessing, and developing children's mathematical thinking: The power of a one-to-one interview for preservice teachers in providing insights into appropriate pedagogical practices. International Journal of Education Research, 37, 211-226. http://dx.doi.org/10.1016/S0883-0355(02)00061-7

Pauen, S., \& Pahnke, J. (2008). Mathematische Kompetenzen im Kindergarten: Evaluation der Effekte einer Kurzzeitintervention [Mathematical skills in preschoolers: evaluating the effects of a short-time intervention]. Empirische Pädagogik, 22, 193-208.

Peter-Koop, A., Wollring, B., Spindeler, B., \& Grüßing, M. (2007). ElementarMathematisches BasisInterview (EMBI). Offenburg: Mildenberger Verlag.

Preßler, A., Krajewski, K., \& Hasselhorn, M. (2013). Working memory capacity in preschool children contributes to the acquisition of school relevant precursor skills. Learning and Individual Differences, 23, 138-144. http://dx.doi.org/10.1016/j.lindif.2012.10.005

Resnick, L. B. (1989). Developing mathematical knowledge. American Psychologist, 44, 162-169. http://dx.doi.org/10.1037/0003-066X.44.2.162

Weinert, F. E., \& Helmke, A. (Hrsg.). (1997). Entwicklung im Grundschulalter[Development during elementary school years]. Weinheim: PsychologieVerlagsUnion. 